\title{
Para entender as imagens: como ver o que nos olha?
}

///////////I Fabrício Silveira ${ }^{1}$

\section{Resenha}

KILPP, S.; FISCHER, G. (orgs.). Para entender as imagens: como ver o que nos olha? Porto Alegre: Entremeios, 2013.

1. Fabrício Silveira é Doutor em Ciências da Comunicação pela Unisinos. Atualmente, é professor dos cursos de graduação e pós-graduação em Comunicação na mesma universidade. Em duas ocasiões, foi pesquisador convidado e professor visitante na Universidade Autônoma de Barcelona. É autor do livro Rupturas Instáveis. Entrar e sair da música pop. Porto Alegre/ RS: Editora Libretos, 2013. Email: fabriciosilveira@terra.com.br. 
Resumo Para entender as imagens: como ver o que nos olha?, livro organizado por Suzana Klipp e Gustavo Fischer, reúne parte dos trabalhos apresentados durante a $11^{\text {a }}$ Semana da Imagem na Comunicação, realizada em maio de 2013, na Universidade do Vale do Rio dos Sinos (Unisinos), em São Leopoldo / RS. É uma tentativa de mapear algumas das novas práticas imagéticas e das novas bases de operação da imagem técnica na cultura contemporânea.

Palavras-chave Audiovisualidade, processos midiáticos, tecnocultura, imagem técnica.

Abstract Understanding images: How to see what sees us?, book edited by Suzana Kilpp and Gustavo Fischer, brings together part of the papers presented during the 1lth Image in Communication Week, held in May 2013 at the University of Vale do Rio dos Sinos (Unisinos), São Leopoldo / RS. It is an attempt to map some of the new imagistic practices and new bases of operation of the technical image in contemporary culture.

Keywords Audiovisuality, media processes, technoculture, technical image. 
Para entender as imagens: como ver o que nos olha? | Fabrício Silveira

Em 1992, o filósofo e historiador Georges Didi-Huberman (2010) tomou emprestado uma expressão de James Joyce - na verdade, um fragmento extraído da fala de Stephen Dedalus, no clássico Ulisses -, alterou-a levemente e utilizou-a como título de um de seus livros: O que vemos, o que nos olha. Com ela, em 1998, foi apresentado ao leitor brasileiro.

Anos depois, a mesma formulação de Didi-Huberman (que, com justiça, deveríamos creditar a Joyce-Huberman, numa insólita e hipotética figura) passa a funcionar também como metáfora indutora e organizadora do conjunto de textos reunidos por Suzana Kilpp e Gustavo Fischer, lançado recentemente, no final de 2013, pela editora Entremeios, de Porto Alegre / RS.

Para entender as imagens: como ver o que nos olha?, o livro em questão, é emblema e resultado da $11^{a}$ Semana da Imagem na Comunicação, realizada em maio de 2013, na Universidade do Vale do Rio dos Sinos (Unisinos), em São Leopoldo / RS. Naquela ocasião, sob os auspícios do TCAv (Audiovisualidades e Tecnocultura: comunicação, memória e design), grupo de pesquisa lotado na casa, coordenado pelos mesmos professores citados, reuniram-se diversos pesquisadores de renome nacional e internacional, tais como Massimo Canevacci, Erick Felinto, Ivana Bentes e Vinícius Andrade Pereira, todos comprometidos com a discussão sobre a visualidade contemporânea, de modo geral, e com o mote específico definido para o encontro.

O livro é um pouco a súmula daquela rica semana de debates - indo bastante além, no entanto, daquilo que poderiam ter sido os Anais do evento. É também o registro da produção efetiva de um 
grupo de estudos muito dedicado e atuante, e é, ainda, uma boa base de operações para futuras parcerias e futuros trabalhos teóricos.

Em síntese, trata-se de publicação bastante representativa do atual estado do campo da Comunicação no Brasil, seja por sua irregularidade, pela dispersão das questões e dos temas que recobre (independentemente do acerto e da oportunidade do recorte), seja por se configurar ou por ganhar impulso (e ordem) justamente a partir de uma metáfora poderosa e um paradoxo evidente, ambos bastante intrigantes. Afinal de contas, como ver o que nos olha? Somos, de fato, observados pelas imagens que nos rodeiam?

A pergunta do título é realmente interessante e desafiadora. Por vários motivos: primeiro, porque é uma provocação direta à reflexão, com seu caráter paradoxal e farsesco se transformando num desafio ao entendimento. A indagação incômoda, prontamente, conduz à polêmica. Trata-se, portanto, de um bom indutor acadêmico. Tratase de um bom chamado e de uma boa sinalização geral para diversos exercícios analíticos, diversos ensaios e tentativas de resposta.

Segundo, porque opera e convoca à atuação num "terreno psicológico", num terreno marcado, em alguma medida, por disposições e angulações psicologicamente orientadas (abertas não só às interfaces com as disciplinas psi, propriamente, mas, sobretudo, aos temas do afeto, da memória, da dimensão sensível, da constituição do sujeito, dentre outras temáticas). Desse modo, nos permite entender que a discussão sobre a imagem não se pode apartar da discussão sobre o imaginário e sobre a economia psíquica que o sustenta e o motiva. Aqui, o tema do olhar, o universo de indagações que ele suscita, bem como o modo como está dito e apresentado, alude ao flerte e ao idílio amoroso - "o amor é um modo de olhar, é ver-se nos olhos do outro, é ver-se observado, furtivamente", teria dito Roland Barthes (2003). É a partir desta lógica da troca de olhares, do olhar retribuído, do espelhamento no outro (seja nas imagens do outro, seja nas imagens como alteridade abissal) que as discussões são propostas. O texto de Massimo Canevacci, por exemplo, é o mais representativo disto que estamos falando. Nele, o antropólogo italiano relata o 
Para entender as imagens: como ver o que nos olha? | Fabrício Silveira

modo como se apaixonou por uma boneca laranja, um manequim de vitrines, encontrado num mercado de pulgas em Belém do Pará.

Mas há ainda, na pergunta-mãe (“como ver o que nos olha?”), uma terceira força que a justifica: há uma pregnância e/ou uma plausabilidade sociológicas muito evidentes, haja vista a enorme proliferação, em nosso cotidiano comezinho, de bordões alusivos à sociedade das imagens, à sociedade do espetáculo, aos imperativos televisivos, à teleficcionalização do real, haja visto o senso comum de que vivemos numa era da visibilidade midiática exponenciada, a ideia de que, hoje, as imagens valem mais do que mil palavras e tantas outras avaliações correntes, já naturalizadas.

De fato, diante de tanta inflação visual, pode ser mesmo produtivo pensar as imagens como sujeitos da cultura e, em contrapartida, nos pensarmos como imagens personificadas, sujeitos objetificados, presos nos próprios regimes de visibilidade que forjaram (ou que forjamos, melhor dito).

Há que se reconhecer, no entanto, que, ao contrário do que pode parecer, à primeira vista, poucos textos se valem da perspectiva epistêmica de Didi-Huberman. Com exceção do texto de Suzana Kilpp, que abre o volume e que, de certo modo, enquadra o restante das leituras, não há nenhuma abordagem exegética mais frontal, elucidativa, que jogue luz interpretativa sobre as formulações de DidiHuberman, que seja capaz de esclarecê-las, debatê-las criticamente e fundar, a partir delas, uma apropriação comunicacional mais própria, mais rigorosa e mais singularizada. Além do capítulo de abertura, o estudo de Jamer Guterres Melo, sobre a lógica do arquivo nas poéticas audiovisuais contemporâneas, é o único que efetivamente lança mão do teórico francês.

No escrito original de James Joyce, a expressão (ver o que nos olha) aparece de um modo muito particular: Dedalus vê o mar e nele vê refletido o rosto de sua própria mãe, recém-falecida. Em DidiHuberman, a expressão refere a uma tensão incômoda e essencial entre observador e objeto (no caso, objeto artístico) observado. Para ele, o objeto artístico nos devolveria o olhar. De algum modo, o olhar 
que lhe reservamos acaba também por nos incluir, reflexivamente, a partir de seu rebatimento na obra de arte.

Aqui, no livro organizado por Kilpp e Fischer, a expressão não está mais orientada à discussão sobre a imagem de arte, um tanto quanto específica, mas às imagens técnicas, definidas segundo Vilém Flusser. Como ponto de partida, há uma abertura disciplinar maior do que aquela visada por Didi-Huberman. Além disso, o debate se reveste de uma orientação metodológica mais marcada, mais instrumental (que, vista de perto, é condizente com as prerrogativas de uma "ciência aplicada", como é o caso da Comunicação, e com o espaço formativo onde a discussão se dá, no âmbito de pesquisas de mestrado e doutorado). Tal orientação metodológica e formativa é evidente desde o título do volume - Para entender as imagens: como ver o que nos olha? -, destacando-se o emprego das expressões para entender e como ver.

Ou seja: se, por um lado, há ganhos reais, na discussão pública que é aberta, no veio interdisciplinar buscado, no insumo às diversas investigações em andamento; por outro, perde-se a tensão dialética fundamental para esclarecer fenômenos artísticos pontuais, como pretendia Didi-Huberman, originalmente. A rigor, para o autor francês nunca se tratou de entender as imagens, as imagens em si, em si mesmas, enquanto formas e campos expressivos definidos e delimitados, mas os sintomas, as forças míticas que elas carregam, a potência fantasmal e intempestiva que fazem sobreviver. Os textos aqui reunidos alinham-se a esta perspectiva e ensaiam os primeiros passos no sentido de ampliá-la, desenvolvendo-a no trato com as mídias, os processos midiáticos e as imagens técnicas.

A irregularidade a qual nos referimos acima não diz respeito unicamente ao nível desigual de aprofundamento teórico alcançado, à diversidade de objetos empíricos, aos resultados analíticos obtidos, às orientações disciplinares invocadas, caso a caso, mas também aos próprios formatos expositivos adotados. Assim, o que temos é um conjunto de short papers somados a artigos mais extensos, creditados, muito compreensivelmente, aos painelistas principais de cada uma 
Para entender as imagens: como ver o que nos olha? | Fabrício Silveira

das noites. Ao final, há uma entrevista realizada com Vinícius Andrade Pereira.

Alguns escritos, de fato, entabulam conversas internas, conversam entre si, voluntária ou mesmo involuntariamente, tais como os três trabalhos sobre cinemagraphs, assinados por Marcelo Salcedo Gomes, Camila Schäfer e Lisiane Cohen. Outros parecem existir - e até fazer sentido, no conjunto geral - sem esforço consciente de ajuste ou de estabelecimento de diálogos mais firmes e direcionados com o núcleo teórico-temático da publicação. Isto ocorre justamente em função do caráter aberto, inclusivo e integrador da proposição geral.

Há, de outra parte, alguns interessantes pontos de contato, por exemplo: o tema da relação entre visualidade e corporalidade; a ênfase na problematização do conceito de tecnocultura; a busca de uma compreensão da visibilidade moderna para além da perspectiva representacional (tal como consagrada pela semiótica textualista e pela iconologia); em decorrência, a tentativa de apreender as imagens num viés não-hermenêutico, as imagens como sistema, como agência, como memória/duração, como afeto e como ambiência, não mais como signo ou como representação, apenas; a presença fantasmática de Walter Benjamin, cruzando o volume, manifestando-se mais ou menos, às vezes como referencial oculto (porém nunca negado, nunca contraditado, pelos diversos movimentos teóricos e analíticos feitos), como presença fantasmal desdobrada ao longo das discussões. Vale dizer, claro, que Benjamin é também um dos pontos fortes da própria matriz de reflexão de Didi-Huberman.

Em síntese, Para entender as imagens: como ver o que nos olha? é uma publicação que aciona uma espécie de "epistemologia da metáfora", que parece ser tão recorrente no campo Comunicacional e que nos faz acreditar, cada vez mais, que a força de um conceito ou de uma ideia tem muito pouco a ver com seu fechamento doutrinário, mas com as provocações que faz, com as linhas de fuga, os nódulos e as micro-variações que instala. 


\section{Referências}

BARTHES, R. Fragmentos de um discurso amoroso. São Paulo: Martins Fontes, 2003.

DIDI-HUBERMAN, G. O que vemos, o que nos olha. $2^{\text {a }}$ ed. São Paulo: Editora 34, 2010.

KILPP, S.; FISCHER, G. (orgs.). Para entender as imagens: como ver o que nos olha? Porto Alegre: Entremeios, 2013.

Recebido em março e aprovado em junho de 2014. 